\title{
Structural Analysis of Magnesium-Aluminium Hydrotalcites Modified with Iron III Obtained by Hydroxide Precipitation Method
}

\author{
Graciele Vieira Barbosa', Maria Aparecida Zaghete ${ }^{2 *}$, Rafael Aparecido Ciola Amoresi², \\ Margarete Soares da Silva ${ }^{3}$, Alberto Adriano Cavalheiro' ${ }^{1}$, Rogério Cesar de Lara da Silva ${ }^{1}$ \\ ${ }^{1}$ CDTEQ - Centro de Desenvolvimento de Tecnologias Químicas, Universidade Estadual de Mato Grosso do Sul, \\ Navirai, Brazil \\ ${ }^{2} \mathrm{CDMF}$ - Centro de Desenvolvimento de Materiais Funcionais, Universidade Estadual Paulista, Araraquara, Brazil \\ ${ }^{3}$ CEPEMAT - Centro de Pesquisas em Materiais, Universidade Estadual de Mato Grosso do Sul, Dourados, Brazil \\ Email: zaghete@iq.unesp.br
}

How to cite this paper: Barbosa, G.V., Zaghete, M.A., Amoresi, R.A.C., Silva, M.S., Cavalheiro, A.A. and Silva, R.C. (2017) Structural Analysis of Magnesium-Aluminium Hydrotalcites Modified with Iron III Obtained by Hydroxide Precipitation Method. Materials Sciences and Applications, 8, 784-797. https://doi.org/10.4236/msa.2017.811057

Received: September 18, 2017

Accepted: October 20, 2017

Published: October 23, 2017

Copyright (c) 2017 by authors and Scientific Research Publishing Inc. This work is licensed under the Creative Commons Attribution International License (CC BY 4.0).

http://creativecommons.org/licenses/by/4.0/

cc) (i) Open Access

\begin{abstract}
Hydrotalcite-type anionic clays are a group of important materials used in adsorption processes, mainly for organic pollutants removal due the layered double hydroxide structure. The layer-interlayer interactions provide a structural memory even after dehydration and dehydroxylation process, since a very stable interlayer anions are part of material composition, like the carbonate one. A limited numbers of trivalent modifier cations can replace the aluminium cation due the ionic radii mismatch or oxidation state restrictions. Transition metal cations can replace the aluminium one in octahedral site of hydroxide lamellas in order to improve the adsorptive behaviors. In this work, we have investigate three compositions of carbonated magnesium-aluminium hydrotalcite with different iron (III) contents through the co-precipitation method at $\mathrm{pH} 11$ and aging step at $60^{\circ} \mathrm{C}$ for 6 hours. Thermal analysis was performed aiming the determination of the hydration water and hydroxyl amounts in dried precipitate samples, taking in account the results obtained for X-ray diffractometry, infrared spectroscopy, and nitrogen adsorption-desorption characterization for several thermally treated samples. All of synthesized samples showed high surface areas, even for high temperature of thermal treatment. The co-substitution with iron (III) reduced the temperature of dehydration and dehydroxylation process, but the co-substitution at $5 \mathrm{~mol} \%$ provides other desirables characteristics, like a more amount of rhombohedral $\mathrm{HDL}$ phase and higher porosity, even after the thermal treatment at $500^{\circ} \mathrm{C}$ for 4 hours. This result makes that composition very applicable as a reusable adsorbent material in order to removal several types of micro-pollutant compounds in aqueous media.
\end{abstract}




\section{Keywords}

Hydrotalcite, Layered Double Hydroxide, Hydroxide Precipitation, Iron (III)

\section{Introduction}

One of the most versatile adsorbent material groups is the synthetic hydrotalcite anionic clays due their wide applications as adsorbents and catalyst support materials, named Layered Double Hydroxide (LDH) [1] [2] [3]. Hydrotalcites have a structure similar to the brucite $\mathrm{Mg}(\mathrm{OH})_{2}$, where the $\mathrm{Mg}^{2+}$ cations are bonded to the six $\mathrm{OH}^{-}$anions, forming an octahedral arrangement. Each $\mathrm{OH}^{-}$anions, in turn, are coordinated to two $\mathrm{Mg}^{2+}$ of vicinal octahedral centers, which results in an poly-octahedral structure similar to sheet with infinite two-dimension. The sheets cannot be directly assembled on one another in order to get a three-dimensional structure because all of the sheet surfaces are positively charged due the terminal protons. Nevertheless, in aqueous media, water and mineral anions, like the carbonate, are able to form an intricate arrangement of hydrogen bonds in order to connect the sheets through the interlayer species and give rise to LDH structure [4] [5] [6].

However, the typical hydrotalcite structures possess some of the $\mathrm{Mg}^{2+}$ cation replaced by trivalent cation, like $\mathrm{Al}^{3+}$ one, which causes a charge unbalancing among the mixed cation centers and terminal $\mathrm{OH}^{-}$groups, leading to the formation of highly positively charged sheets. Thus, to stabilize this type of hydrotalcite LDH structure, a proportional amount of interlayer anions is required to compensate the positive charge in the layer. There is a wide variety of LDH structure, because the interlayer species can be adjusted in order to compensate the amount of trivalent cations. Hence, the compositions can be controlled by the general formula $\left[\mathrm{M}_{1-\mathrm{x}}^{2+} \mathrm{M}_{\mathrm{x}}^{3+}\left(\mathrm{OH}^{-}\right)_{2}\right]^{\mathrm{x}+}\left[\mathrm{A}^{\mathrm{n}-}\right]_{\mathrm{x} / \mathrm{n}} \cdot \mathrm{yH}_{2} \mathrm{O}$ [7] [8] [9].

The carbonated magnesium-aluminium hydrotalcite is the typical anionic clay easily prepared in the laboratory. Avery stable structure can be obtained carrying the $\mathrm{Mg} / \mathrm{Al}$ ratio between 4 and 2, which means, according to the general formula, a x value of 0.2 and 0.33 , respectively. The most of hydrotalcite compositions are solid solutions not well established and is very usual the same compositions present significant fluctuations in their physical properties. The most of LDH hydrotalcites possess structural memory against the dehydration process, because the cross-linked hydroxyl group and interlayer carbonate anion remains intact in dehydrated structure. On the other hand, the dehydroxylation process occurs only above $350^{\circ} \mathrm{C}$ and leads to the formation of disordered structure with interstitial cations. However, depending of the hydrotalcite composition, part of the LDH structure can remain intact even the dehydroxylation process [10] [11] [12] [13].

Extra modifications can be carried out by insertion of other trivalent cations, such as $\mathrm{Mn}(\mathrm{III}), \mathrm{Cr}(\mathrm{III})$, and $\mathrm{Fe}(\mathrm{III})$ in total or partial substitutions to the alu- 
minium ones [14]-[20]. However, the changing in divalent cation site is more difficult, because the magnesium plays an important role in structural memory of $\mathrm{LDH}$ phases [21] [22] [23]. By considering the hydrotalcites compositions with magnesium content adjusted between 67 and 80 mol\%, the structure memory becomes high and the $\mathrm{LDH}$ phase resists to the dehydration process and even to the dehydroxylation around $350^{\circ} \mathrm{C}$. Only when the carbonate interlayer specie starts go out in temperatures close to $500^{\circ} \mathrm{C}$, is that occurs a pronounced migration of magnesium from octahedral to tetrahedral sites, which leads to structure collapse [24] [25] [26]. The $\mathrm{Fe}^{3+}$ cation possesses lower ionic radii mismatch with $\mathrm{Mg}^{2+}$ than the $\mathrm{Al}^{3+}$ one [27] and the differences among the ionic radii are also responsible by structure strains and by the mechanism of compression-expansion process, which lead to significant changes in surface area and porosity [28] [29] [30].

The most simple and versatile methodology to synthesize hydrotalcite powder samples is the co-precipitation method based on the addition of inorganic metallic salt solutions on the alkaline precipitant solution. Structural morphology depends on the $\mathrm{pH}$ of aging after precipitation. For carbonated magnesium-aluminium hydrotalcites, the $\mathrm{pH}$ range must set between 10 and 11 and the aging step is carried out under vigorous stirring until from 3 to 18 hours at $60^{\circ} \mathrm{C}$. It is necessary a filtration step of the aged precipitate followed by washing with distilled water until the complete soluble sodium salts and final drying at $100^{\circ} \mathrm{C}$ [31]. The $\mathrm{Fe}^{3+}$ and $\mathrm{Al}^{3+}$ cations have very similar physical-chemical characteristics concerning the $\mathrm{pH}$ of precipitation, which makes the synthesis procedure of carbonated magnesium-aluminium-iron hydrotalcites very similar to the typical magnesium-aluminium hydrotalcites [32].

In this work, we aim to prepare three compositions of carbonated magnesium-aluminium-iron hydrotalcites through the co-precipitation method at $\mathrm{pH}$ 11 in order to investigate the influence of iron (III) co-substitution on the structural and morphologic stabilities along the increasing in the temperature of thermal treatment.

\section{Materials and Methods}

\subsection{Sample Synthesis}

The hydrotalcite samples were obtained by co-precipitation method at $\mathrm{pH} 11$, according to the formula $\left[\mathrm{Mg}_{0.70}^{2+} \mathrm{Al}_{0.30-\mathrm{y}}^{3+} \mathrm{Fe}_{\mathrm{y}}^{3+}\left(\mathrm{OH}^{-}\right)_{2}\right]^{0.30+}\left[\mathrm{CO}_{3}^{2-}\right]_{0.15}$, with y set as $0,0.05$, and 0.10, which were named as HTF00, HTF05, and HTD10 sample, respectively. Firstly, it was prepared the cation aqueous solutions by dissolution of hexahydrate $\mathrm{Mg}\left(\mathrm{NO}_{3}\right)_{2} \cdot 6 \mathrm{H}_{2} \mathrm{O}$, aluminium III nitrate nonahydrate $\mathrm{Al}\left(\mathrm{NO}_{3}\right)_{3} \cdot 9 \mathrm{H}_{2} \mathrm{O}$, and iron III nitrate nonahydrate $\mathrm{Fe}\left(\mathrm{NO}_{3}\right)_{3} \cdot 9 \mathrm{H}_{2} \mathrm{O}$ in distilled water. The stoichiometric calculations were carried out in order to get cation molar sum $\left(\mathrm{Mg}^{2+}+\right.$ $\mathrm{Al}^{3+}+\mathrm{Fe}^{3+}$ ) equal to $1.0 \mathrm{~mol} \cdot \mathrm{L}^{-1}$. In sequence, it was prepared the anion precipitant aqueous solutions by dissolution in distilled water of sodium hydroxide $(\mathrm{NaOH})$ and sodium carbonate $\left(\mathrm{Na}_{2} \mathrm{CO}_{3}\right)$. 
Both solutions were slowly poured on the third flask kept under vigorous stirring at room temperature. For precipitate aging process, each precipitate suspension batch was heated at $60^{\circ} \mathrm{C}$ for 6 hours under moderate stirring and finally filtered and washed with distilled water until neutral $\mathrm{pH}$ for supernatant solution. The washed precipitate samples were dried at $100^{\circ} \mathrm{C}$ for 24 hours and slightly crushed in a porcelain mortar in order to get the powders desagglomeration. In sequence, each dried precipitate samples was divided in three parts and lead to thermal treatment at different temperatures $\left(100^{\circ} \mathrm{C}, 200^{\circ} \mathrm{C}\right.$ and $\left.500^{\circ} \mathrm{C}\right)$ for 4 hours. The thermal treatment at $100^{\circ} \mathrm{C}$ for 4 hours for samples already dried at $100^{\circ} \mathrm{C}$ for 24 hours aims to normalize the powder processing among all of the samples. The appearance and powder colors for all of the samples as a function of iron (III) content and of temperature of thermal treatment can be seen on Figure 1.

\subsection{Characterization Techniques}

Each dried precipitate samples was analyzed by simultaneous (TG/DTA) technique by using a Netszch Thermische Analyse (TASC 414/2 controller), alpha-alumina standard, Pt 10 thermocouple, synthetic air flux of $30 \mathrm{~cm}^{3} \cdot \mathrm{min}^{-1}$ and heating rate of $10^{\circ} \mathrm{C} \cdot \mathrm{min}^{-1}$. All of the thermally treated samples were lead to $\mathrm{X}$-ray diffraction technique using D5005Siemens equipment, with $\mathrm{K}$-alpha $\mathrm{Cu}$ radiation in 2-theta range from $20^{\circ}$ to $80^{\circ}$. All of the phases were identify by comparing the patterns with the JCPDS data bank [33]. The main functional groups and its variations were analyzed by FTIR spectrophotometer with Nexus 650 Thermo Nicoletequipped with photo-acoustic detector for solid samples. The nitrogen adsorption-desorption isotherm at $77 \mathrm{~K}$ was carried out using ASAP 2010 Micromeritics equipment. The pore size distribution in the mesopore-macropore range was calculated by $\mathrm{BJH}$ model [34] and the specific area by BET one [35].

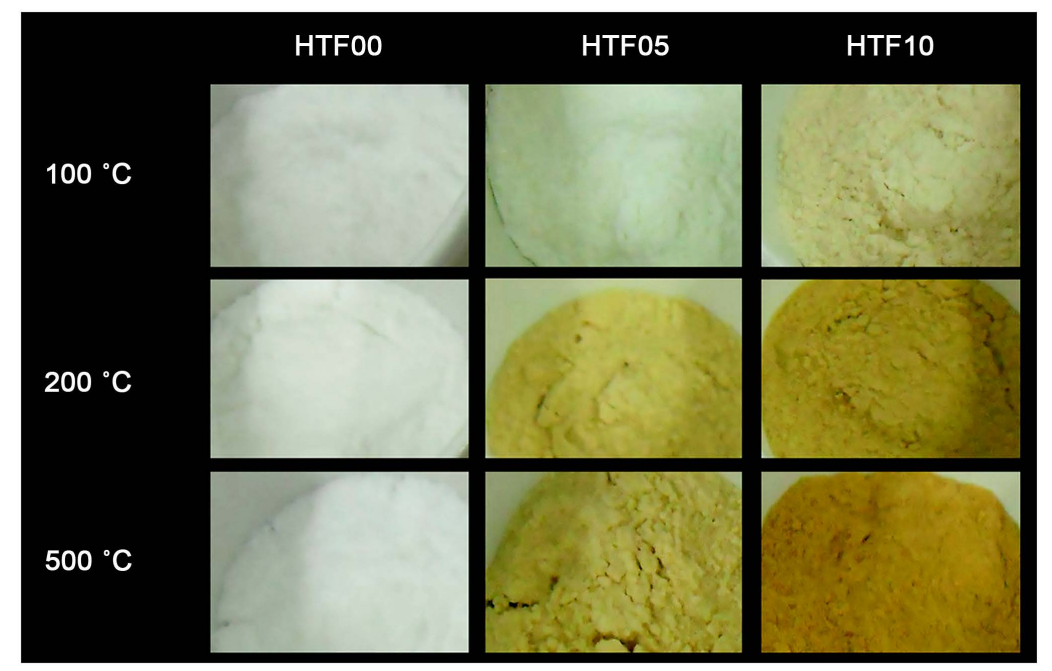

Figure 1. Powder colors for carbonated magnesium-aluminium hydrotalcites varying as a function of iron (III) content and of temperature of thermal treatment. 


\section{Results and Discussion}

Thermal properties of the dry precipitates for each composition investigated by simultaneous TGA/DTA analysis are shown in Figure 2. There are three curves (TGA, DTG and DTA) for each sample, which is identified by a different color. It is possible to observe the four weight losses, which are notably changed as a function of iron content. The dehydration and dehydroxylation processes have more evidenced endothermic behavior due the narrower temperature range for these steps. However, the other two processes also endothermic behavior, but is broader due the kinetic component influence. The first weight loss starts at room temperature due the water vapor dragging by the airflow of analysis. That residual drying occurring up to $100^{\circ} \mathrm{C}$ for all of the samples seems not to be dependent on the iron (III) content, but probably is a function of differences in the inter-particle morphology. The weight losses for the first process are shown in first column of the Table 1 .

In sequence, the dehydration of interlayer spaces starts to occur above $100^{\circ} \mathrm{C}$ and extends up to $260^{\circ} \mathrm{C}$ for HTF00 sample. The final temperature of the dehy-

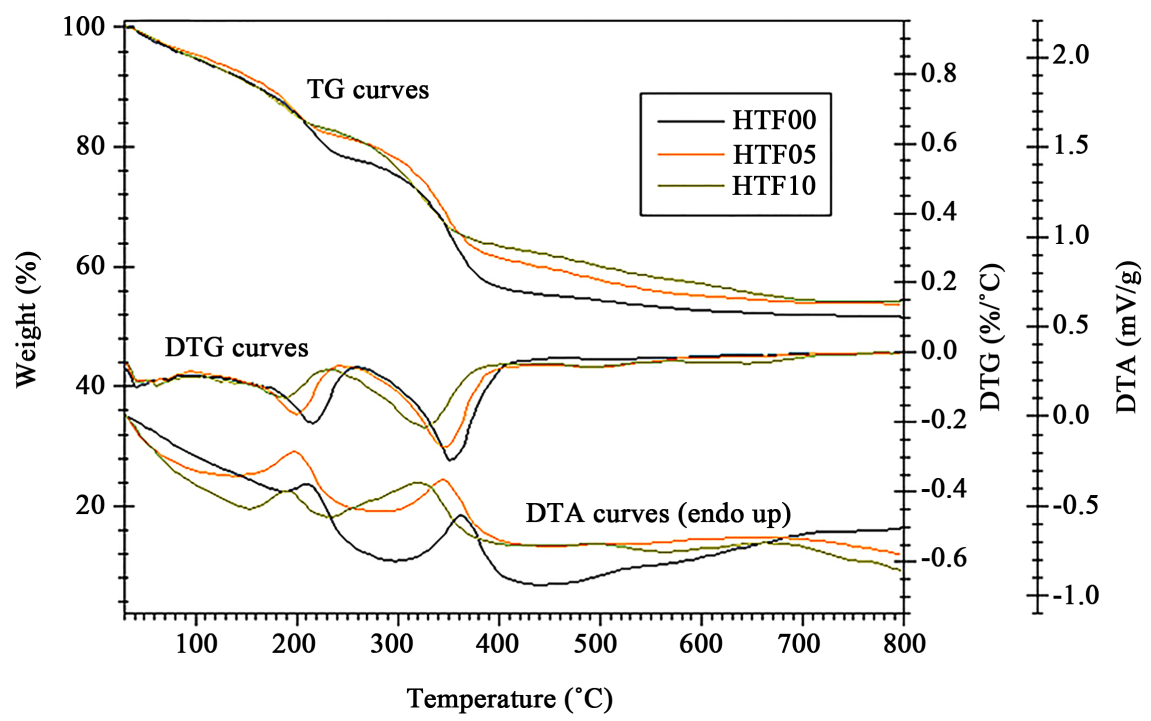

Figure 2. Thermal analyses (TG/DTA) for carbonated magnesium-aluminium-iron hydrotalcite precipitate samples dried at $100^{\circ} \mathrm{C}$ for 24 hours.

Table 1. Weight losses and DTG peaks for the thermal events observed TG/DTG curves of carbonated magnesium-aluminium-iron hydrotalcite dried precipitates.

\begin{tabular}{cccccc}
\hline & \multicolumn{5}{c}{ Thermal events } \\
\cline { 2 - 6 } Sample & $\begin{array}{c}\text { Residual } \\
\text { drying up } \\
\text { to } 100^{\circ} \mathrm{C}(\%)\end{array}$ & $\begin{array}{c}\text { Dehydration } \\
(\%) / \mathrm{DTG} \\
\text { peak }\left({ }^{\circ} \mathrm{C}\right)\end{array}$ & $\begin{array}{c}\text { Dehydroxylation } \\
(\%) / \mathrm{DTG} \text { peak }\left({ }^{\circ} \mathrm{C}\right)\end{array}$ & $\begin{array}{c}\text { Decarbonation } \\
\text { up to } 800^{\circ} \mathrm{C}(\%)\end{array}$ & $\begin{array}{c}\text { Residue } \\
(\%)\end{array}$ \\
\hline HTF00 & 5.2 & $17.3 / 240$ & $22.3 / 350$ & 3.5 & 51.7 \\
HTF05 & 4.8 & $13.8 / 200$ & $22.4 / 340$ & 5.9 & 53,1 \\
HTF10 & 5.5 & $11.6 / 185$ & $21.0 / 330$ & 7.8 & 54.1 \\
\hline
\end{tabular}


dration process is displaced to lower temperatures for HTF05 and HTF10 samples, as shown in DTG curves, followed by a similar changing in the maximum of weight loss (DTG peak), as shown in the second column of the Table 1. The relation between water loss and the iron content in the samples seems to be inversely proportional, which it is coherent because the calculated y values, according to the general formula $\left[\mathrm{Mg}_{0.70}^{2+} \mathrm{Al}_{0.30-\mathrm{x}}^{3+} \mathrm{Fe}_{\mathrm{x}}^{3+}\left(\mathrm{OH}^{-}\right)_{2}\right]^{0.30+}\left[\mathrm{CO}_{3}^{2-}\right]_{0.15} \cdot \mathrm{yH}_{2} \mathrm{O}$, were 0.7 for all of the samples.

The third thermal event is the layer dehydroxylation process through the water loss originated from the condensation of hydroxyl groups, which originate metallic oxide mixture in material thermally treated above that temperature range [36] [37]. In spite of the weight loss not to be noticed dependence with iron (III) content among the samples, the final temperature and the DTG peak for that process are displaced to lower temperatures, as shown in the third column of the Table 1 . Theoretical value for weight loss in dehydroxylation step is between $29 \%$, for HTF00 sample and 27\%, for HTF10 one.

Thus, part of hydroxyl groups are eliminated previously at lower temperature in overlapping with the dehydration process, once the final decarbonation step is also lower than theoretical values. If was considering the theoretical calculations for carbon dioxide loss are close to $13 \%$ then a similar overlapping with dehydroxylation step is very probable. Nevertheless, the iron (III) co-substitution seems to retain more amounts of interlayer carbonate anions than no co-substituted one. The final residue is very similar to the theoretical calculations.

In Figure 3 are shown the X-ray diffraction patterns for three samples of carbonated magnesium-aluminium-iron hydrotalcites thermally treated at $100^{\circ} \mathrm{C}$, $200^{\circ} \mathrm{C}$ and $500^{\circ} \mathrm{C}$ for 4 hours. The peak set for all of the samples thermally treat-

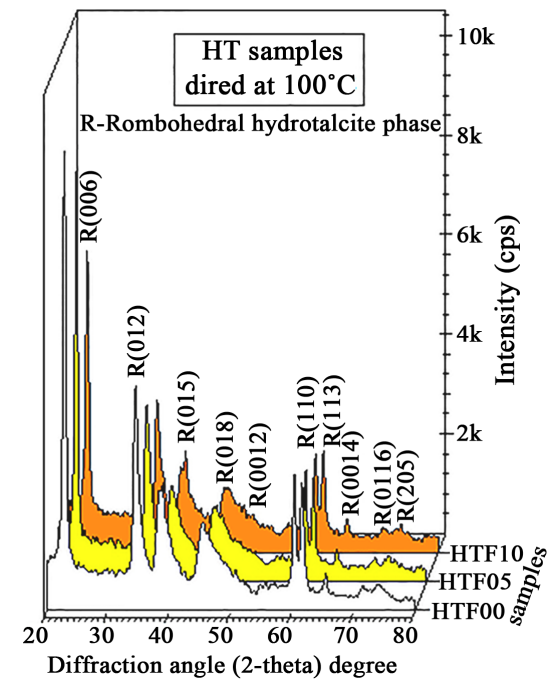

(a)

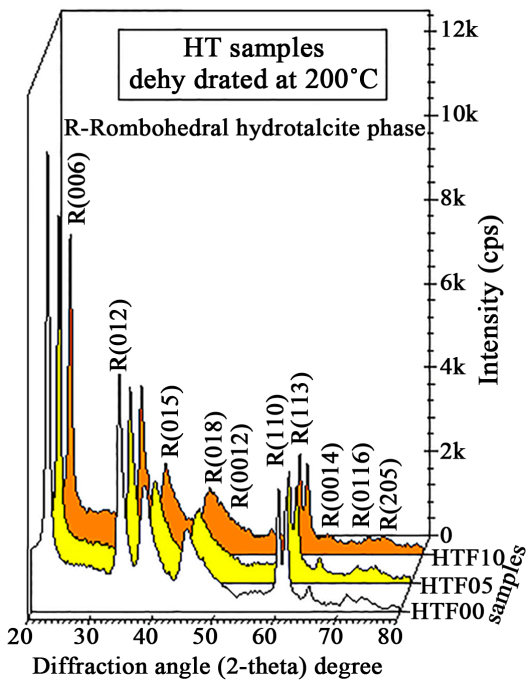

(b)

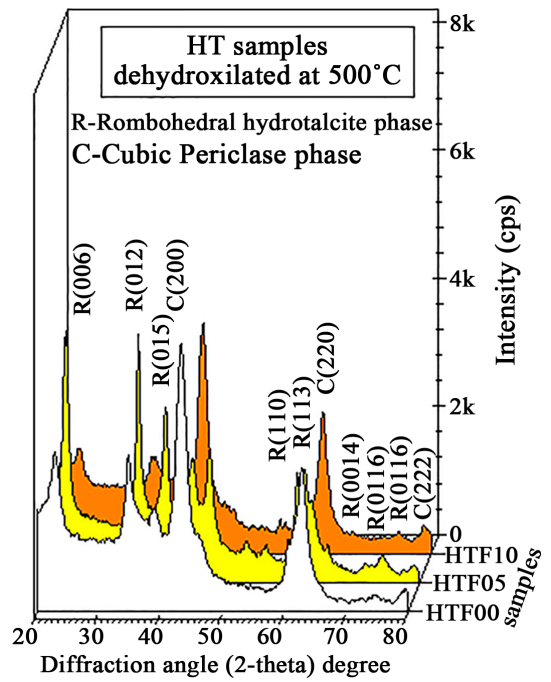

(c)

Figure 3. X-ray diffraction patterns for carbonated magnesium-aluminium-iron hydro-talcite precipitate samples thermally treated at different temperatures for 4 hours: (a) drying at $100^{\circ} \mathrm{C}$; (b) dehydration at $200^{\circ} \mathrm{C}$; and (c) dehydroxylation at $500^{\circ} \mathrm{C}$. 
ed at $100^{\circ} \mathrm{C}$ and $200^{\circ} \mathrm{C}$ is very similar to the $\mathrm{R}-3 \mathrm{~m}$ rhombohedral $\mathrm{LDH}$ structure and matches with JCPDS card 89 - 461 [33]. Taking in account the (006) peak position at $22.8^{\circ}$ (2-theta), it is possible to observe a continuous decreasing along the increasing of iron (III) content and that event occurs for low-temperature thermally treated samples $\left(100^{\circ} \mathrm{C}\right.$ and $\left.200^{\circ} \mathrm{C}\right)$. No odd peak in relation to the hydrotalcite single phases was found in X-ray diffraction patterns for these samples. On the other hand, the peak intensities become higher when the temperature of thermal treatment increases from 100 (Figure $3(\mathrm{a})$ ) to $200^{\circ} \mathrm{C}$ (Figure 3(b)) for all of the compositions. At $500^{\circ} \mathrm{C}$ (Figure 3(c)), the $\mathrm{LDH}$ structure undergoes partial decomposition, giving origin to some amounts of secondary periclase MgO phase (JCPDS card 45 - 946). Nevertheless, the intensity for the (006) peak is considerable higher when compared to the other samples thermally treated at $500^{\circ} \mathrm{C}$, which permits to concludes the LDH structure for HTF05 sample is more stable than the one for other samples.

These results obtained from X-ray diffraction technique seems to be satisfactorily coherent with FTIR spectrometry ones, as shown in Figure 4. The bands signaled as 1, 2, 3, 6 and 8 are originated from different energetic modes of $\mathrm{O}-\mathrm{H}$ groups, while the band signaled as 5 is associated to liquid water bending and the bands signaled as 4 and 7 are related to carbon-oxygen bonds in carbon dioxide and carbonate anions. Details for different modes are available on the text inside the figures.

After the dehydration process between 100 (Figure $4(\mathrm{a})$ ) and $200^{\circ} \mathrm{C}$ (Figure $4(\mathrm{~b})$ ), it is possible to observe the proportional decreasing in the intensity of the band 3, associated to the $\mathrm{O}-\mathrm{H}$ symmetric stretch of water. In addition, there is the proportional increasing in the intensity of the band 6 , associated to the $-\mathrm{OH}$ bending vibration. These aspects means the interlayer residual species are rear

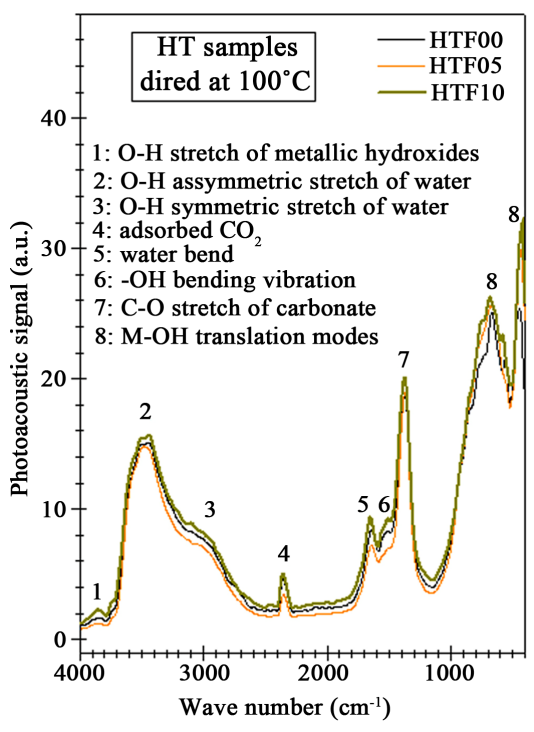

(a)

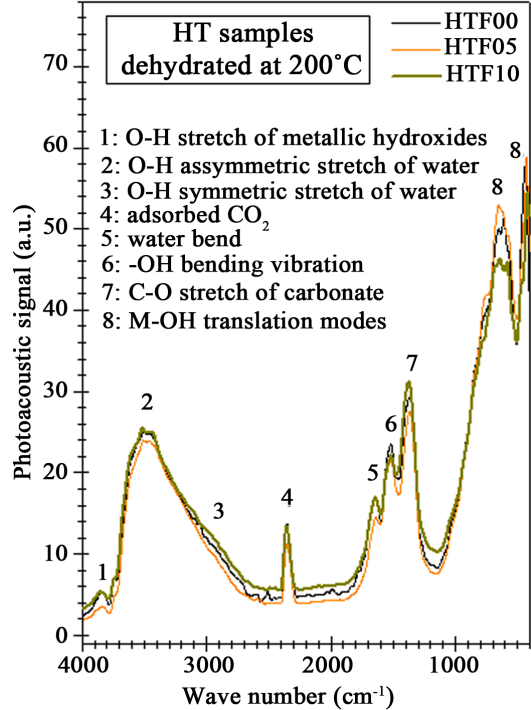

(b)

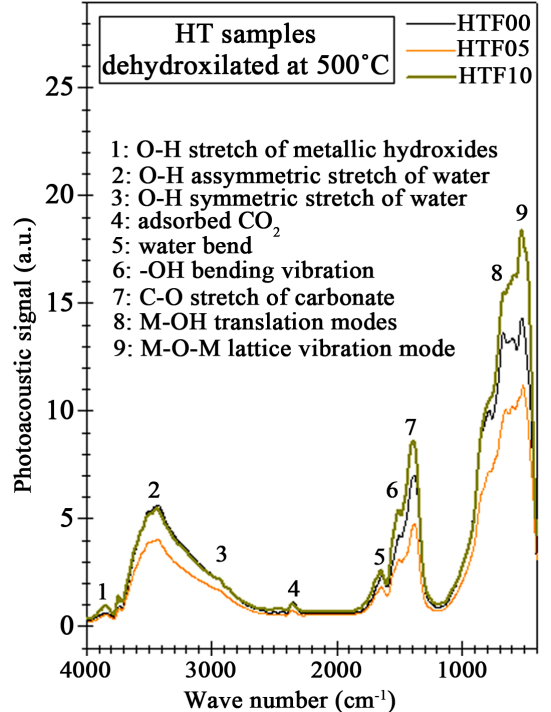

(c)

Figure 4. FTIR spectra for carbonated magnesium-aluminium-iron hydrotalcite precipitate samples thermally treated at different temperatures for 4 hours: (a) drying at $100^{\circ} \mathrm{C}$; (b) dehydration at $200^{\circ} \mathrm{C}$; and (c) dehydroxylation at $500^{\circ} \mathrm{C}$. 
ranged during the dehydration, which lead to better ordering of LDH structure, according to X-ray diffraction data. After the dehydroxylation process at $500^{\circ} \mathrm{C}$ (Figure 4(c)), all of the bands originated from different energetic modes of $\mathrm{O}-\mathrm{H}$ groups undergo the proportional decreasing in their intensities. It is possible to observe the intensities of the bands 4 and 7 are also proportionally reduced, meaning the part of carbon dioxide and carbonate amounts go out during the dehydroxylation process.

That evidence is coherent with lower value for decarbonation than theoretical calculations, as previously discussed about the thermal analysis data. Besides these changes, a new band associated to the M-O-M lattice vibration mode (band 9) raises for all of the samples, but that event is more noticed for HTF00 and HTF10 samples, due more amount of secondary periclase $\mathrm{MgO}$ phase.

The isotherms of nitrogen adsorption-desorption at $77 \mathrm{~K}$ for all of the samples are shown in Figure 5. The type IV isotherm is characteristic of the natural anionic clays, which is generally associated with capillary condensation in mesopores [38] [39] [40]. The isotherms observed for the synthetic carbonated magnesium-aluminium-iron hydrotalcite samples prepared in this work seems to be very similar with the natural clay ones, mainly for high volume adsorbed at relative pressures, which is characteristic of external surface area and macropore contributions. Nevertheless, there is a considerable volume absorbed at relative pressures between 0.7 and 0.9 , which is characteristic of the mesopores. No considerable volume adsorbed uptake is observed for any samples, what means the hydrotalcite samples do not have micropores or small mesopores. The dehydrated HTF00 sample presents higher volume absorbed than dried one, as can be observed by comparing the Figure 5(a) and Figure 5(b), but during the dehy-

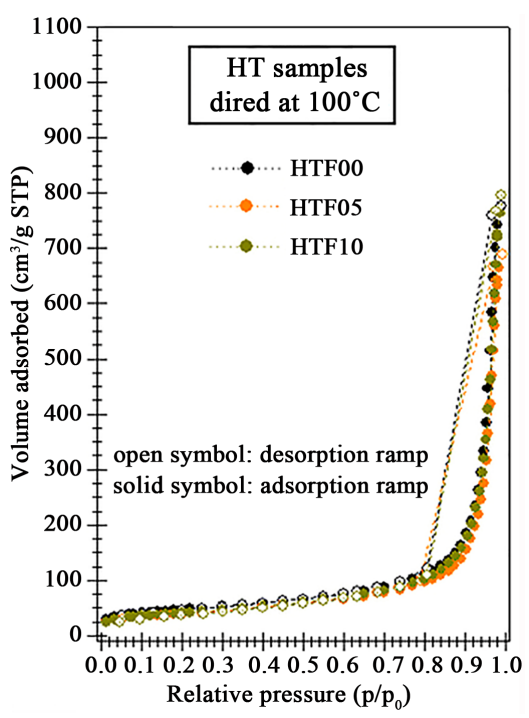

(a)

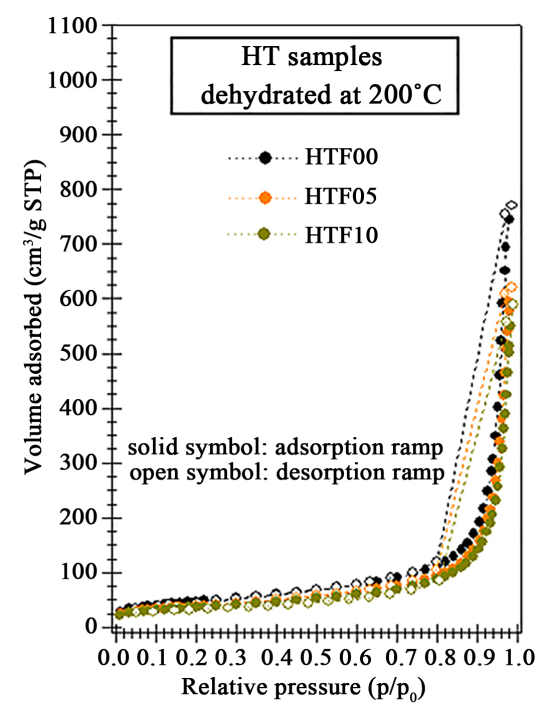

(b)

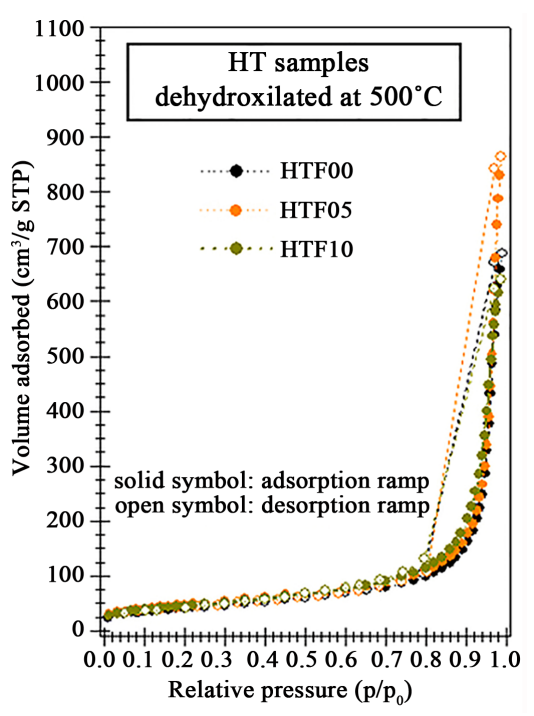

(c)

Figure 5. Nitrogen adsorption-desorption isotherms at $77 \mathrm{~K}$ for carbonated magnesium- aluminium-iron hydrotalcite precipitate samples thermally treated at different temperatures for 4 hours: (a) drying at $100^{\circ} \mathrm{C}$; (b) dehydration at $200^{\circ} \mathrm{C}$; and (c) dehydroxylation at $500^{\circ} \mathrm{C}$. 
droxylation at $500^{\circ} \mathrm{C}$, the volume adsorbed turns to decrease (Figure $5(\mathrm{c})$ ). These volume adsorbed variation at high relative pressures seems to be inverse for iron (III) co-substituted samples, once the dehydration tends to decrease the volume adsorbed, while the dehydroxylation one, leads to increase of them.

The morphologic behavior observed through the nitrogen adsorption-desorption at $77 \mathrm{~K}$, can be better understand on the Figure 6, which shows a strict correlation between BET specific area and volume adsorbed variations for all of the samples. At low temperatures of thermal treatment $\left(100^{\circ} \mathrm{C}\right.$ and $\left.200^{\circ} \mathrm{C}\right)$, the adsorptive characteristics are better for no co-substituted sample, presenting surface area close $160-165 \mathrm{~m}^{2} / \mathrm{g}$. However, at $500^{\circ} \mathrm{C}$, the iron (III) co-substi- tuted samples present also similar surface area. The dehydration process for iron (III) co-substituted samples seems to be morphological harmful, due to particle sintering during the dehydration. As consequence, the sintered powders are disrupted by the water vapor evolution at $500^{\circ} \mathrm{C}$, leading to increasing in specific area again.

In Figure 7 are observed the $\mathrm{BJH}$ pore size distribution in mesopore (2 to 50 $\mathrm{nm})$ and macropore $(>50 \mathrm{~nm})$ regions. The higher incremental pore volumes are very broad for all of the samples and tend to localize in mesopore-macropore boundary (at $50 \mathrm{~nm}$ ). For HTF00 and HTF05 samples, the incremental pore volumes does not changes during the dehydration process, as can be observed comparing the Figure 7(a) and Figure 7(b), but for the dehydroxylation process at $500^{\circ} \mathrm{C}$ (Figure $7(\mathrm{c})$ ), the $\mathrm{HTF} 05$ sample turns the more porous sample among all of the others. On the other hand, the HTF10 sample presents a continuous decreasing in incremental pore volume in the mesopore region, reaching to present practically no mesoporosity at $500^{\circ} \mathrm{C}$.

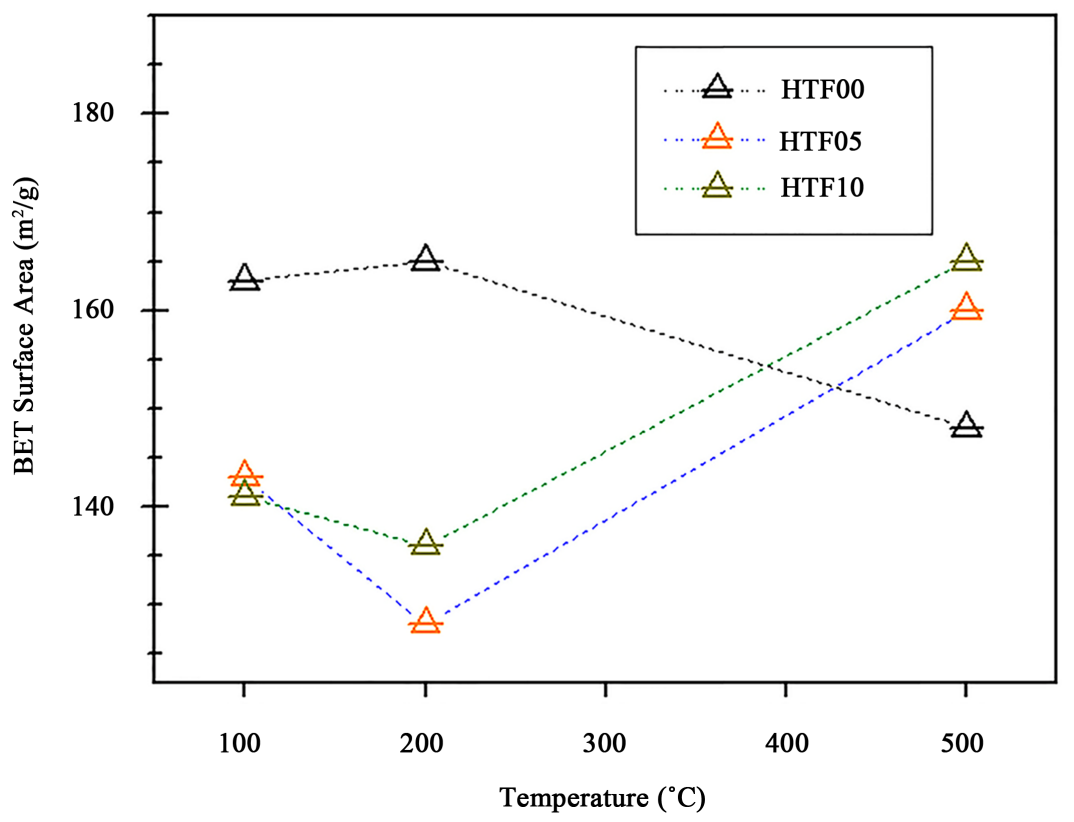

Figure 6. Evolution of BET surface area for carbonated magnesium-aluminium-iron hydrotalcite precipitate samples along the temperature of thermal treatement for 4 hours. 


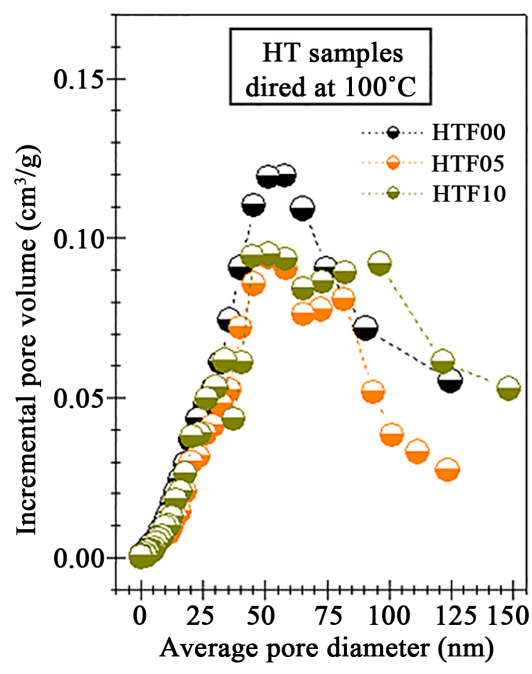

(a)

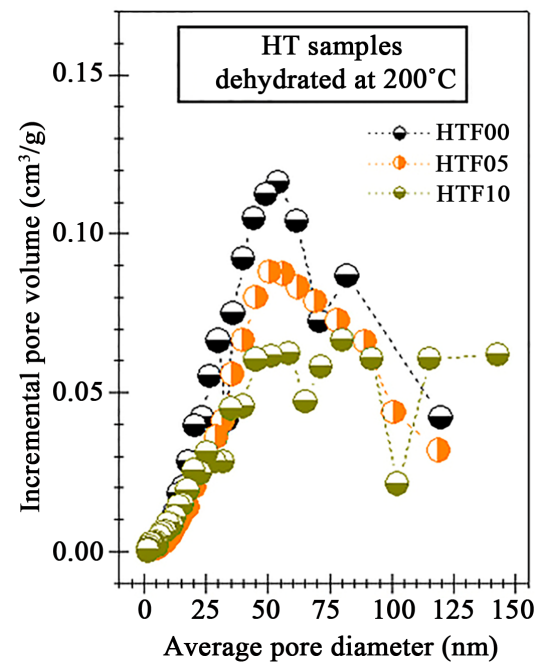

(b)

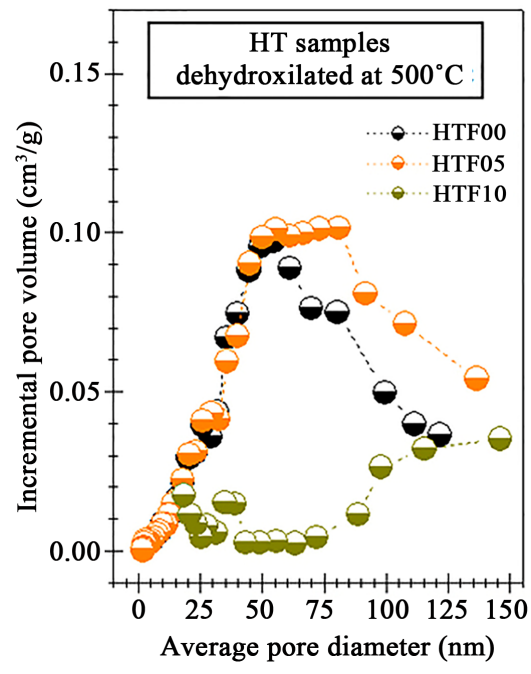

(c)

Figure 7. BJH pore size distribution patterns for carbonated magnesium-aluminium-iron hydrotalcite precipitate samples thermally treated at different temperatures for 4 hours: (a) drying at $100^{\circ} \mathrm{C}$; (b) dehydration at $200^{\circ} \mathrm{C}$; and (c) dehydroxylation at $500^{\circ} \mathrm{C}$.

These results about the porosity of thermally treated samples seem to be strongly associated with the remaining rhombohedral LDH hydrotalcite phase after the dehydroxylation at $500^{\circ} \mathrm{C}$. In fact, the X-ray diffraction patterns are very coherent with proposition. On the other hand, there is no substantial decreasing for the incremental pore volume associated to large macropores $(>100$ $\mathrm{nm}$ ), what makes the HTF10 sample moderately stable only against the particle sintering during the dehydroxylation process. Thus, is very probable the periclase phase becomes more macroporous when it is resulted from the hydrotalcite co-substituted with $10 \mathrm{~mol} \%$ of iron (III).

\section{Conclusion}

From obtained results, it can be concluded the carbonated magnesium-aluminium-iron hydrotalcite presents full inherent structural and morphological properties of anionic clay adsorbent materials, including the rhombohedral phase with satisfactory crystallinity, structural stability against the dehydration process, high surface areas, and large porosity with pore size predominant in mesopore-macropore boundary region. It was possible to observe the iron (III) co-substituted samples provide better surface area after dehydroxylation process. However, by considering the pore size distribution and the structural stability for thermally treated LDH rhombohedral phase, the insertion of $5 \mathrm{~mol} \%$ of iron (III) seems to be the best composition. For lower temperatures of thermal treatment, the no co-substituted sample has still the best set of structural and morphological characteristics, taking in account the adsorbent applications. However, the lower temperatures for dehydration and dehydroxylation process for the samples co-substituted with $5 \mathrm{~mol} \%$ of iron (III) can be associated to the lowering of chemisorption heats in interlayer spaces. Under the point view of reversi- 
ble process, that composition can be better applicable as reusable adsorbent material due the facilities for desorption steps, so that is a good suggestion for future works.

\section{Acknowledgements}

The authors thank the Brazilian foundations FUNDECT-MS, CNPq, CAPES and FINEP for financial supports.

\section{References}

[1] Wiyantokoa, B., Kurniawatia, P., Purbaningtias, T.E. and Fatimah, I. (2015) Synthesis and Characterization of Hydrotalcite at Different $\mathrm{Mg} / \mathrm{Al}$ Molar Ratios. Procedia Chemistry, 17, 21-26. https://doi.org/10.1016/j.proche.2015.12.115

[2] Nguyen, H.K.D., Nguyen, T.D., Hoang, D.N., Dao, D.S., Nguyen, T.T., Wanwisa, L. and Hoang, L.L (2007) X-Ray Absorption Spectroscopies of Mg-Al-Ni Hydrotalcite Like Compound for Explaining the Generation of Surface Acid Sites. Korean Journal of Chemical Engineering, 34, 314-319.

https://doi.org/10.1007/s11814-016-0285-1

[3] Lukashin, A.V., Vertegel, A.A., Eliseev, A.A., Nikiforov, M.P., Gornert, P. and Tretyako, Y.D. (2003) Chemical Design of Magnetic Nanocomposites Based on Layered Double Hydroxides. Journal of Nanoparticle Research, 5, 455-464. https://doi.org/10.1023/B:NANO.0000006087.95385.81

[4] Ardhayantia, L.I. and Santosa, S.J. (2016) Synthesis of Magnetite-Mg/Al Hydrotalcite and Its Application as Adsorbent for Navy Blue and Yellow F3G Dyes. Procedia Engineering, 148, 1380-1387. https://doi.org/10.1016/j.proeng.2016.06.609

[5] Rodilla, J.M., Neves, P.P., Pombala, S., Rives, V., Trujillano, R. and Díezc, D. (2015) Hydrotalcite Catalysis for the Synthesis of New Chiral Building Blocks. Natural Product Research, 30, 834-840. https://doi.org/10.1080/14786419.2015.1075525

[6] Hafshah, H., Prajitno, D.H. and Roesyadi, A. (2017) Hydrotalcite Catalyst for Hydrocracking Calophyllum inophyllum Oil to Biofuel: A Comparative Study with and without Nickel Impregnation. Bulletin of Chemical Reaction Engineering \& Catalysis, 12, 273-280. https://doi.org/10.9767/bcrec.12.2.776.273-280

[7] Sikander, U., Sufian, S. and Salam, M.A. (2017) A Review of Hydrotalcite Based Catalysts for Hydrogen Production Systems. International Journal of Hydrogen Energy, 42, 19851-19868. https://doi.org/10.1016/j.ijhydene.2017.06.089

[8] Fahami, A., Al-Hazmib, F.S., Al-Ghamdib, A., Mahmoudb, W.E. and Beall, G.W (2016) Structural Characterization of Chlorine Intercalated Mg-Al Layered Double Hydroxides: A Comparative Study between Mechanochemistry and Hydrothermal Methods. Journal of Alloys and Compounds, 683, 100-107.

https://doi.org/10.1016/j.jallcom.2016.05.032

[9] Crepaldi, E.L. and Valim, J.B. (1998) Hidróxidos Duplos Lamelares: Síntese, Estrutura, Propriedades e Aplicações. Química Nova, 21, 300-311. https://doi.org/10.1590/S0100-40421998000300011

[10] Miyata, S. (1980) Physico-Chemical Properties of Synthetic Hydrotalcites in Relation to Composition. Clays and Clay Minerals, 28, 50-56. https://doi.org/10.1346/CCMN.1980.0280107

[11] Rowland, R.A. (1951) Differential Thermal Analysis of Clays and Carbonates. Clays and Clay Technology, 169, 151-163. 
[12] Niu, M., Qiu, M., Han, Q. and Wang, Y. (2016) The Influence on Synthetising $\mathrm{Mg}-\mathrm{Al}$ Hydrotalcite by using Different $\mathrm{Mg}$ and $\mathrm{Al}$ Sources as the Precursors. American Chemical Science Journal, 15, 1-7. https://doi.org/10.9734/ACSJ/2016/27767

[13] Belloto, M., Rebours, B., Clause, O., Lynch, J., Bazin, D. and Elkaïn, E. (1996) Hydrotalcite Decomposition Mechanism: A Clue to the Structure and Reactivity of Spinel like Mixed Oxides. The Journal of Physical Chemistry, 100, 8535-8542. https://doi.org/10.1021/jp960040i

[14] Yang, C., Liao, L., Lv, G., Wu, L., Mei, L. and Li, Z. (2016) Synthesis and Characterization of Mn Intercalated Mg-Al Hydrotalcite. Journal of Colloid and Interface Science, 479, 115-120. https://doi.org/10.1016/j.jcis.2016.06.057

[15] Velu, S. and Swamy, C.S. (1997) Effect of Substitution of Fe3+/Cr3+ on the Alkylation of Phenol with Methanol over Magnesium-Aluminium Calcined Hydrotalcite. Applied Catalysis A: General, 162, 81-91. https://doi.org/10.1016/S0926-860X(97)00086-0

[16] Prakash, A.S., Kamath, V. and Hegde, M.S. (2000) Synthesis and Characterization of the Layered Double Hydroxides of Mg with Cr. Materials Research Bulletin, 35, 2189-2197. https://doi.org/10.1016/S0025-5408(00)00419-0

[17] Labajos, F.M. and Rives, V. (1996) Thermal Evolution of Chromium (III) Ions Hidrotalcite like Compounds. Inorganic Chemistry, 34, 5313-5318. https://doi.org/10.1021/ic951648t

[18] Ma, W., Zhao, N., Yang, G., Tian, L. and Wang, R. (2011) Removal of Fluoride Ions from Aqueous Solution by the Calcination Product of Mg-Al-Fe Hydrotalcite-like Compound. Desalination, 268, 20-26. https://doi.org/10.1016/j.desal.2010.09.045

[19] Yang, Y., Gao, N., Chu, W., Zhang, Y. and Ma, Y. (2012) Adsorption of Perchlorate from Aqueous Solution by the Calcination Product of $\mathrm{Mg} /(\mathrm{Al}-\mathrm{Fe})$ Hydrotalcite-like Compounds. Journal of Hazardous Materials, 209-210, 318-325. https://doi.org/10.1016/j.jhazmat.2012.01.026

[20] Kato, M., Azimi, M.D., Fayaz, S.H., Shah, M.D., Hoque, M.Z., Hamajima, N., Ohnuma, S., Ohtsuka, T., Maeda, M. and Yoshinaga, M. (2016) Uranium in Well Drinking Water of Kabul, Afghanistan and Its Effective, Low-Cost Depuration using Mg-Fe Based Hydrotalcite-Like Compounds. Chemosphere, 165, 27-32. https://doi.org/10.1016/j.chemosphere.2016.08.124

[21] Carpani, I., Berrettoni, M., Giorgetti, M. and Tonelli, D. (2006) Intercalation of Iron(III) Hexacyano Complex in a Ni, Al Hydrotalcite-Like Compound. The Journal of Physical Chemistry B, 110, 7265-7269. https://doi.org/10.1021/jp0574910

[22] Debek, R., Motak, M., Galvez, M. E., Grzybek, T, Da Costa, P. and Pieńkowski, L. (2017) Ceria Promotion over Ni-Containing Hydrotalcite-Derived Catalysts for CO2 Methane Reforming. E3S Web of Conferences, 14, 02039.

https://doi.org/10.1051/e3sconf/20171402039

[23] Carpentier, J., Siffert, S., Lamonier, J.F., Laversin, H. and Aboukais, A. (2007) Synthesis and Characterization of $\mathrm{Cu}-\mathrm{Co}-\mathrm{Fe}$ Hydrotalcites and Their Calcined Products. Journal of Porous Materials, 14, 103-110. https://doi.org/10.1007/s10934-006-9014-1

[24] Puttaswamy, N.S. and Kamath, V. (1997) Reversible Thermal Behavior of Layered Double Hydroxides a Thermogravimetric Study. Journal of Materials Chemistry, 7, 1941-1945. https://doi.org/10.1039/a701911d

[25] Beck, C.W. (1950) Differential Thermal Analysis Curves of Carbonate Minerals. American Mineralogist, 35, 985-1013.

http://www.minsocam.org/ammin/AM35/AM35_985.pdf 
[26] Baskaran, T., Christopher, J. and Sakthivel, A. (2015) Progress on Layered Hydrotalcite (HT) Materials as Potential Support and Catalytic Materials. RSC Advances, 5, 98853-98875. https://doi.org/10.1039/C5RA19909C

[27] Shannon, R.D. (1976) A Revised Effective Ionic Radii and Systematic Studies of Interatomic Distances in Halides and Chalcogenides. Acta Crystallographica, A32, 751-767. https://doi.org/10.1107/S0567739476001551

[28] Tamura, H., Chiba, J., Ito, M., Takeda, T., Kikkawa, S., Mawatari, Y. and Tabata, M. (2006) Formation of Hydrotalcite in Aqueous Solutions and Intercalation of ATP by Anion Exchange. Journal of Colloid and Interface Science, 300, 648-654. https://doi.org/10.1016/j.jcis.2006.04.007

[29] Ebitani, K., Motokura, K., Mori, K., Mizugaki, T. and Kaneda, K. (2006) Reconstructed Hydrotalcite as a Highly Active Heterogeneous Base Catalyst for Carbon-Carbon Bond Formations in the Presence of Water. The Journal of Organic Chemistry, 71, 5440-5447. https://doi.org/10.1021/jo0603451

[30] Bhat, B.M. (2012) Synthesis and Characterization of Hydrotalcite and Hydrotalcite Compounds and Their Application as a Base Catalyst for Aldol Condensation Reaction. Oriental Journal of Chemistry, 28, 1751-1760.

https://doi.org/10.13005/ojc/280426

[31] Timofeeva, M.N., Kapustin, A.E., Panchenko, V.N., Butenko, E.O., Krupskaya, V.V., Gil, A. and Vicente, M.A. (2016) Synthetic and Natural Materials with the Brucite-Like Layers as High Active Catalyst for Synthesis of 1-Methoxy-2-Propanol from Methanol and Propylene Oxide. Journal of Molecular Catalysis A: Chemical, 423, 22-30. https://doi.org/10.1016/j.molcata.2016.06.006

[32] Lide, D.R. (2007) Handbook of Chemistry and Physics. 87th Edition, Taylor and Francis, Boca Raton.

[33] JCPDS Joint Committee on Powder Diffraction Standards/International Center for Diffraction Data (2003) Pennsylvania, Powder Diffraction File 2003.

[34] Landers, J., Gor, G.Y. and Neimark, A.V. (2003) Density Functional Theory Methods for Characterization of Porous Materials. Colloids and Surfaces A: Physicochemical and Engineering Aspects, 437, 33.

[35] Marsh, H. and Rand, B. (1970) Adverse Criticism of the Use of the t-Plot to Characterize Microporosity. Journal of Colloid and Interface Science, 33, 478-479. https://doi.org/10.1016/0021-9797(70)90244-4

[36] Vágvölgyi, V., Palmer, S.J., Kristóf, J., Frost, R.L., and Horváth, E. (2008) Mechanism for Hydrotalcite Decomposition: A Controlled Rate Thermal Analysis Study. Journal of Colloid and Interface Science, 318, 302-308. https://doi.org/10.1016/j.jcis.2007.10.033

[37] Wright, C.M.R., Ruengkajorn, K., Kilpatrick, A.F.R., Buffet, J.-C. and O’Hare, D. (2017) Controlling the Surface Hydroxyl Concentration by Thermal Treatment of Layered Double Hydroxides. Inorganic Chemistry, 56, 7842-7850. https://doi.org/10.1021/acs.inorgchem.7b00582

[38] Alvarez Acevedo, N.I., Rocha, M.C.G. and Bertolino, L.C. (2017) Mineralogical Characterization of Natural Clays from Brazilian Southeast Region for Industrial Applications. Cerâmica, 63, 253-262. https://doi.org/10.1590/0366-69132017633662045

[39] Santos, R.M.M., Tronto, J., Briois, V. and Santilli, C.V. (2017) Thermal Decomposition and Recovery Properties of ZnAl-CO3 Layered Double Hydroxide for Anionic Dye Adsorption: Insight into the Aggregative Nucleation and Growth Mechanism of the LDH Memory Effect. Journal of Materials Chemistry A, 5, 9998-10009. 
https://doi.org/10.1039/C7TA00834A

[40] Olfs, H.-M., Torres-Dorante, L.O., Eckelt, R. and Kosslick, H. (2009) Comparison of Different Synthesis Routes for Mg-Al Layered Double Hydroxides (LDH): Characterization of the Structural Phases and Anion Exchange Properties. Applied Clay Science, 43, 459-464. https://doi.org/10.1016/j.clay.2008.10.009 